\title{
Pacific Connections: Language and Literary Studies, Challenges and Developments at the National University of Samoa
}

\author{
Sina Va'ai
}

\begin{abstract}
This paper discusses the challenges and developments in the domain of language and literary studies at the National University of Samoa (NUS) in Apia. One of three universities in this Pacific Island nation, it is branded as the premiere national tertiary institution in the country. NUS was founded in 1984 by an Act of Parliament with a \$5 Samoan Tala (ST) equivalent to \$3 USD budget, a Foundation Programme with 45 students and 7 Faculty members amidst much controversy and national debate as to the need and sustainability of such an institution. With the help of Japanese Aid, NUS moved to a new much expanded campus and physical facilities and has now grown in the last 32 years to a roll of several thousand students, 300 staff (both academic and administration) and an annual budget of over ST $\$ 10$ million. The challenges and developments at NUS are many and varied, particularly in the field of language and literary studies in English given that for the majority of students English is a second language. For school-leavers who enter their Foundation Programme, English is a compulsory subject and whilst the founding ethos of NUS is to promote and advance studies relating to Samoa, including Samoan language and culture, the forces of post-colonialism and globalisation impacting on the Pacific region demand that students be competent in the international language of English. This has led to the recent introduction since 2012 of curricular initiatives to address declining competencies in English, especially in the field of reading and comprehension.
\end{abstract}

Index Terms-National University of Samoa, challenges, developments, language, literary studies.

\section{INTRODUCTION}

In late 2016, Disney launched its first animated movie with a Pacific cast, context, musical repertoire and story line. Moana tells the Pacific story of peoples who are wayfarers, ocean voyagers with their mythical heroes and demigods like Maui or Tiitii-a-talaga as the Samoans know him. International and local reviews have been quite positive as Pacific Islanders see visual representations of themselves and the story of Moana, the local heroine who saves her people by restoring the heart of Tewhiti which Maui had mischievously stolen, causing the deterioration and destruction of the Pacific Ocean environment with all its marine and natural resources. The values of balance, connections, courage and family are clearly emphasized with the voyaging song "We Know the Way." The three lines of the song, "We know where we are, We know who

Manuscript received December 30 2016; revised June 17, 2017.

Sina Va'ai is with the Faculty of Arts, National University of Samoa, Samoa (e-mail: smtvaai@yahoo.com). we are and We know the way" particularly resonate in these post-colonial times and for this article about Pacific connections and the challenges and developments at the National University of Samoa (NUS) especially in relation to the promotion of language and literary studies, vital ingredients for national identity, security and peace.

Samoa hosted the $3^{\text {rd }}$ United Nations (UN) Small Island Developing States (SIDS) Conference in 2014 and since 2015 UN countries have moved from focusing on Millennium Development Goals (MDG's) to promoting 17 Sustainable Development Goals (SDG's) to achieve peace and prosperity across the globe. Goal 4 is to 'ensure inclusive and equitable education and promote life-long learning opportunities for all," (p. 1) [1]. Education for sustainable development is thus a priority for SIDS like Samoa and the challenges and developments at NUS, one of three universities in this Pacific Island nation and branded as the premier national tertiary institution are thus vital concerns for all stakeholders, especially in the field of literacy and literary empowerment.

\section{NUS: ITS ESTABLISHMENT AND ITS DEVELOPMENT IN A NUTSHELL}

NUS had very humble beginnings, even though established by in 1984 by an Act of Parliament but with determination, drive and political will 'developed in leaps and bounds' (p.45) [2] from 45 students in the University Preparatory Year (UPY) Programme (now renamed the Foundation programme), minimum academic and administrative staff of 7 and a budget passed in Parliament of $\$ 5.00$ Samoan Tala (ST) equivalent to \$3.00 USD approximately, many members of the community who were invited to Stakeholder Consultations in the founding year expressed grave doubts about the sustainability of such a venture. Others thought the budget was a joke and they were not sure who would have the last laugh. However, over the last 32 years, with the assistance of foreign donors, such as the Japanese and Chinese Governments, NUS has a new much expanded main campus, since Semester 2, 1997, increasing physical facilities and has grown to have a roll of 3278 students (full and part-time) in 2016 and an annual budget of ST\$10, 209, 260.00 million for the Financial Year 2016/2017, (p.1) [3].

\section{The NATIONAL CONTEXT}

It is important to outline briefly the national context for the Education Sector of which NUS is one of three partners together with the Ministry of Education, Sports and Culture 
(MESC) and the Samoa Qualifications Authority (SQA). This Sector serves a total population of 195, 516 [4] with 143 primary schools and 23 \{Government\} secondary schools with a school population in 2015 of 57, 992 with 41, 250 at the primary level, (p.12) [5]. Samoan and English are the two official languages of the nation and full bilingual competence is the ideal, expectation and goal. However, Kral (2010) in a survey about the status of English in Samoa noted that even though the official MESC policy of additive bilingualism was sound, its implementation was 'problematic', (p.6) [6]. He commented further that several factors contributed to students' underachievement in all subjects, including 'a shortage of qualified teachers at primary and secondary levels, lack of student textbooks, \{and \} poorly equipped and overcrowded classrooms,' (p.6) [6]. His conclusions were a wake-up call, "As these students enter the job market or university or vocational training, they find themselves unable to communicate in English or to use the language as a tool for advancement. At every level of transition, from primary school to high school, or from high school to the workplace, or high school to university, remedial training in English is necessary for most of the youth," (p. 6) [6]. The need for national action was made clear, "Though English is an official language of Samoa, only a portion of the population can use it with full competence. In this regard, the status of English in Samoa is no different from that in many other countries that have designated English as an official language, e.g. India, Pakistan, Philippines, Malaysia among others. In each of those countries, the national governments have recognised the deterioration of English language skills among their broad populations and since the 1980's and 1990's they have used resources to halt this decline," (p. 6) [6]. Measures to address this decline included The Pacific Benchmarking for Education Results (PaBER) programme which was introduced in 2012 "to improve the quality of education and student performance across the Pacific and in particular to respond to low levels of literacy and numeracy," (p. 4) [5]. In summing up the national picture for primary schools in Samoa in 2012, the researchers found that a significant number of the students assessed were at the critical level in literacy (over 50\%) and over a third (36\%) in numeracy (p. 5) [5]. In one of the 3 main domains of enquiry, namely Curriculum and Materials, it was evident that the official policy of additive bilingualism was having a decided detrimental 'effect on student literacy in English', (p. 19) [5]. Teachers preferred to work with the Samoan version of curriculum materials, thus teaching [mainly] in Samoan pointing to a lack of confidence and comfort with their own levels of English language proficiency. The results of the 2012 and 2015 Pacific Islands Literacy and Numeracy Assessments (PILNA) demonstrated the results of this bilingual policy where in 2012, 30\% of Year 6 students assessed in English across the Pacific Region were achieving expected levels of literacy compared to only $8 \%$ of Year 6 students in Samoa and similar results emerged for the 2015 local cohort (p.19) [5].

\section{Setting The ScEne AT NUS: Challenges AND DEVELOPMENTS}

Given the concern over literacy levels at the primary and secondary levels, it is no surprise that the flow -on challenges and necessary developments at NUS are multiple, dynamic and varied in nature. This is particularly evident because of the fruits of bilingualism at the lower rungs of the educational ladder in the field of language and literary studies in English given that for the majority of students, English is a second language or other tongue with the mother tongue being the indigenous language of Samoan. For school-leavers who enter their Foundation Programme, English is a compulsory subject and whilst the founding ethos of NUS is to promote and advance studies relating to Samoa, including Samoan language and culture, the forces of post-colonialism and globalisation impacting on the Pacific region demand that students be competent in the international language of English. This has led to the recent introduction since 2012 of curricular initiatives to address declining competencies in English, especially in the field of reading and comprehension as well as the inclusion of competency in English and Samoan languages as one of the important attributes in a recently approved NUS Graduate Profile in 2016 leading to the Senate resolution that for all undergraduate degrees, from 2017 onwards, HEN107 English for Academic Purposes will be a compulsory course of every Degree Programme.

\section{TURning The SPOTLIGHT ON CONCERNS ABOUT ENGLISH LANGUAGE COMPETENCIES}

The English and Foreign Languages (EFL) Department is currently one of three departments within the Faculty of Arts and operates within the mandate of the National University of Samoa's vision, mission, goals and values, particularly in its attempts to promote an "environment conducive to superior learning, quality teaching, professional training and robust research opportunities that are responsive to the economic and social development of Samoa," (p.4) [7]. It also aims to provide "a variety of intellectual challenges and learning experiences which will be stimulating and rewarding for all concerned in keeping with the major thrust of the University's mission, that is, to provide for the training needs of Samoa", (p.1) [8]. It is still the largest department in the Faculty with 12 full time Faculty lecturers out of a total of 29 and delivers courses for students from all six Faculties of the University; Arts, Education, Business \& Entrepreneurship, Medicine, Nursing and Science and the Centre of Samoan Studies.

The Department objectives are spelt out in the Strategic and Corporate Plans of the Faculty of Arts in the National University of Samoa. Overall, they aim at achieving excellence in academic standards, promoting learning, scholarship, research and creative activities as prominent components as well as hiring, upgrading and growing Faculty who are excellent lecturers, robust scholars, active researchers and creative individuals. The objectives also target and include the preparation of graduates who are well qualified, responsible and well prepared citizens for contemporary local and global challenges especially in promoting communities in which all members are treated with respect and establishing "a University milieu that supports and nourishes the personal, intellectual, physical and social development of the student, promoting effective 
communication amongst all members of the individual's environmental and cultural responsibility and promoting a safe, healthy, clean and supportive environment," (p.1) [9].

Since the Faculty's first External Review of 2005, various developments have occurred which have impacted on the Department, primarily in implementing the recommendations of the Review with regards to the introduction of an additional compulsory Minor of 4 courses for the Bachelor of Arts increasing the total for the degree to 24 courses and the EFL Department offering of HEN107 English for Academic Purposes as a part of the package for this new Minor. This course is also offered for all first year students across all Faculties and Centres and has been utilized since 2006 as such, particularly by students from the Faculties of Education and Science. As mentioned earlier, it is also now mandatory for the other 4 Faculties to incorporate HEN107 into their academic programmes from 2017.

Moreover, "bridging the gap between secondary and tertiary studies have been quite challenging over the years as school leavers often expect spoon-feeding and constant surveillance of their progress," (p.25) [10]. The Department continues to face the challenges of "weaning the school leaver from this dependent mentality" (p.25) [10] through various means including one to one counselling and tutoring as well as extra hours of small group work to encourage completion and achievement.

\section{The InITIAL READING STUDY AND ITS CONSEQUENCES}

In the past decade, concerns with literacy and reading competencies in English increased particularly since for the majority of students, English is a second language. These discussions resulted in a study conducted by members of the EFL Department which was published in 2010, [11]. Two Student/Self Reading Assessment (SRA) Reading Laboratories were used as a tool in this research project to aid in evaluating the level of reading competencies of first year students in the Foundation Certificate Programme which comprises Year 13 students form 36 local secondary schools and colleges who sit and pass the national examinations recently renamed the Samoa School Leaving Certificate (SSLC). From 1990 to 2012, students from Samoa and other Pacific Island nations sat the Pacific Secondary School Certificate (PSSC) coordinated and examined by the South Pacific Board of Educational Assessment (SPBEA) headquartered in Suva, Fiji. From the time Samoa regained its political independence from New Zealand in 1962 till 1990, secondary school leaving students in Samoa and in many Pacific countries sat the New Zealand University Entrance Examinations administered and examined externally by the New Zealand Education Ministry. From 2013, the Year 12 and Year 13 national examinations have been localised, administered and examined in Samoa by MESC.

The findings of the study were quite alarming in respect of the average hours that respondents spent reading outside of class and the reading ages which were well below par. On average the majority of respondents spent one extra hour per week reading outside of class time and reading ages were, on average equivalent to those of Year 9 students or 13 year olds. Subsequent to this study confirming the reality of inadequate reading competencies of Foundation students to cope with tertiary level texts and with departmental discussion of its implications, a budget request of WST $\$ 25,000$ was made in 2013 to purchase a further 12 SRA boxes to implement a new curriculum strategy concerning reading competencies for first year students in the Foundation Certificate Programme.

This Certificate Programme is made up of Year 13 students from 34 - 40 (the figure varies due to problems with staffing and resources) local high schools and colleges on the two main islands of Savaii and Upolu who sit and pass SSLC, the end of year national exams which entitles them to enrol at the National University of Samoa in the following year. The students must obtain a pass mark of Grade 1-4 in English and 3 other subjects giving a total aggregate of 4-15 for enrolment in the Foundation Certificate Programme in any of the five Faculties (Arts, Commerce, Education, Nursing, Science) as well as a General Certificate stream where students must pass Foundation English and Samoan Language plus 6 other Foundation courses selected from across the disciplines offered at the University resulting in 7 streams: Foundation Certificate Arts, FCA, Foundation Certificate Agriculture, FCAg, Foundation Certificate Education FCE, Foundation Certificate Commerce, FCC, Foundation Certificate Science, FCS, Foundation Certificate Nursing, FCN, Foundation Certificate General, FCG. (The grade scale is from 1-10, 1 being the highest and 4 representing a grade band of around $50 \%$ ) Some students will present with a fail grade $(5-6)$ in the English subject but have the relevant total aggregate that allows them to enroll in the Foundation Certificate course. Bridging courses are thus available in the Department of English \& Foreign Languages which provide for these students who do not make the grade either through the English course or through the total aggregate score.

The research team also implemented 'the Proficiency in English Language Test (PELT) starting Semester 1 2013, focussing on the two skills of reading and writing. This test was not intended as a placement or entry test into the NUS Foundation English courses since the entry criteria was already set based on PSSC, now SSLC results \{but rather\} as an indicator of competencies in reading and writing and a red flag for extra tutorial attention where required,' (pp. 2526) [10]. It was also agreed that a second PELT test be administered at the end of Semester to assess the progress of students.

\section{VII.INTRODUCING SRA LABORATORY ASSESSMENT}

The goals of the SRA laboratory have been used for decades in the Pacific and have a proven track record of promoting improvements in literacy globally with five clear goals; 'Firstly, to develop comprehension, vocabulary, fluency, word analysis and study skills. Secondly to reinforce specific skills in which students may show a weakness, thirdly, to interest students in reading and to enlarge their specific knowledge using a wide array of quality factual and fictional selections. Fourthly, to develop the habit of independent work and fifthly to develop the sense of personal responsibility as students take charge of 
their own learning," (p.6) [12].

Generally SRA Laboratories have three Levels: Level 1 targets primary school students, Level 2 secondary school students and Level 3 tertiary students. Since 2010, local literacy champions, particularly Ms Fiti Leung Wai, the Manager of Samoa Stationery and Books (SSAB) in collaboration with MESC have promoted the use of SRA Laboratories in classrooms at all levels of the school system with some success and the initiative by the EFL Department to introduce the SRA laboratories as part of the Foundation English Course Internal Assessment Tasks to promote and enhance reading and comprehension competencies in English joined this growing eruption of concern at declining levels of literacy in English and taking steps to help improve the national situation in this regard.

The SRA placement test was conducted in the first tutorial hour and it showed the majority of students attaining high marks that placed them on the upper end of the reading colour chart initially. However, as the first and second reading cards progressed, it became evident that many students were not coping with the initial placement level and therefore needed to be placed further down the scale of reading colour levels that are more appropriate and for them to work their way up the levels to completion of the required number of cards. 'Students were required in 2013 to read a total of 10 multilevel cards in the appropriate colour level, and to answer a multiplicity of questions that comprises comprehension and structural word analysis and meaning. To ensure that students treated this exercise with serious intent, the activity was made part of the Internal Assessment worth $15 \%$, along with others such as essay writing, note taking and a research project to comprise the $50 \%$ total Course Mark. An overwhelming majority, $92.4 \%$, of the students passed this part of the Internal Assessment. The students that failed did so primarily because they did not complete the required number of cards within the allotted time period,' (p.28) [10]. SRA Assessment continued in this fashion to 2014 but was amended in '2015-16, due to $20 \%$ plus increases in student enrolment, \{when $\}$ a different approach was adopted with students reading 5 compulsory cards, chosen from varying increasing levels of difficulty and were allotted a mark value of $2 \%$ each, or $10 \%$ in total given under test conditions in tutorial classes,' (p. 4) [13]. The impressive pass rate for the SRA exercise for the initial cohort and following cohorts lead the researchers to conclude that the "SRA Laboratories can be an important tool to provide vital, cumulative assistance in building increasing competencies in reading and writing in English", (p.41) [10].

\section{Discussion OF RESULTS FOR SEMESTER 1, 2016}

The conclusions derived from this exercise confirms the PELT test as relevant and necessary for the purpose of establishing an overall and preliminary indication of the proficiency and competencies demonstrated by every new intake of Foundation students that enrol, in contradistinction to their SSLC results.

Table II indicates two thirds of the students passed the SRA reading activities per card based on the totals of the Comprehension (10 marks) and Learn about Words Section worth 33 marks. Noticeable from the results are the number of students who missed out or were not in attendance when the exercise was in progress, which increased as the Semester was nearing the mid-term break. Incidentally, the number of missed assessments increases upward with the colour (Green and Purple) and difficulty level. Absenteeism therefore categorically contributed to and explains the failure rate that occurred in this assessment. The numbers and percentage for the failed articles is relatively consistent within the 5 colours which is also indicative of the level of difficulty in the readings. Even though the overall volume of missed articles was high, determination by number of individuals involved and the Faculty concerned indicated crucial information that is relevant to the Faculties for future consideration, as the following Table I demonstrates, especially for the Faculty of Education whose graduates will bear the onus of teaching the nation's future school-age population, and the Faculty of Nursing whose graduates will be dealing with matters of life and death, (p. 10) [13]. It is clear from Tables III and IV that the results are consistent with the final exams: the FCS showing the highest number of students and percentage pass rate overall and within their own Faculty. The research assignment is the assessment task requiring the most attention and focus: the discrepancies are noticeable between SRA and Research results with FCE barely passing at $52 \%$ and FCN at $49 \%$, indicating "that about half the number of students did not attempt the research project and the implications are many and serious, usually of material resources in addition to students' attitudes and levels of motivation," (p. 10) [13].

TABLE I: PELT RESULTS PER FACULTY

\begin{tabular}{lllll}
\hline & Totals & Passes & Language & Writing \\
\hline FCA & 23 & $17-74 \%$ & $14-61 \%$ & $19-83 \%$ \\
\hline FCE & 48 & $13-27 \%$ & $11-23 \%$ & $23-47 \%$ \\
\hline FCG & 31 & $13-42 \%$ & $14-45 \%$ & $11-35 \%$ \\
\hline FCN & 25 & $8-32 \%$ & $8-32 \%$ & $14-56 \%$ \\
\hline FCC & 22 & $13-59 \%$ & $12-55 \%$ & $17-77 \%$ \\
\hline FCS & 15 & $10-67 \%$ & $12-80 \%$ & $11-73 \%$ \\
\hline \hline
\end{tabular}

TABLE II: MisSES, FAILURES AND PASSES PER ARTICLE

\begin{tabular}{ccccc}
\hline \hline & Article & Passed & Failed & Missed \\
\hline Gold & 1 & $587-66 \%$ & $222-25 \%$ & $77-9 \%$ \\
\hline Tan & 2 & $610-69 \%$ & $229-26 \%$ & $55-6 \%$ \\
\hline Lime & 3 & $610-69 \%$ & $206-23 \%$ & $69-8 \%$ \\
\hline Green & 4 & $590-66 \%$ & $163-18 \%$ & $121-14 \%$ \\
\hline Purple & 5 & $589-66 \%$ & $168-19 \%$ & $117-13 \%$ \\
\hline Totals & & $2986-67 \%$ & $998-22 \%$ & $439-10 \%$ \\
\hline \hline
\end{tabular}

The implications of these results for the compulsory English course HENO04 in the Foundation Certificate programme are that the PELT test should continue in order to provide some indication of English language competencies in reading and writing. Entry levels are currently being reviewed for 2017 in an attempt to improve the quality of students entering university programmes. Moreover, the inclusion of the SRA component as an important part of the course assessment likewise will 
continue so that students can appreciate the importance of acquiring appropriate reading competencies in achieving academic success at tertiary level.

TABLE III: OVERALL PASSES IN HEN004 SRA \& RESEARCH ESSAY

\begin{tabular}{ccccc}
\hline \hline & \multicolumn{2}{c}{ SRA Pass/Fail } & \multicolumn{2}{c}{ RESEARCH Pass/Fail } \\
\hline FCA (173) & $136-16 \%$ & $37-4 \%$ & $109-13 \%$ & $64-8 \%$ \\
\hline FCC (101) & $87-10 \%$ & $14-2 \%$ & $77-9 \%$ & $24-3 \%$ \\
\hline FCE (155) & $108-13 \%$ & $47-6 \%$ & $81-10 \%$ & $74-9 \%$ \\
\hline FCG (174) & $143-17 \%$ & $31-4 \%$ & $109-13 \%$ & $65-8 \%$ \\
\hline FCN (77) & $55-7 \%$ & $22-3 \%$ & $38-5 \%$ & $39-5 \%$ \\
\hline FCS (160) & $149-18 \%$ & $11-1 \%$ & $118-14 \%$ & $42-5.5 \%$ \\
\hline Totals (849) & $681-80 \%$ & $168-20 \%$ & $537-63 \%$ & $312-37 \%$ \\
\hline \hline
\end{tabular}

TABLE IV: TOTAL PASSES IN SRA \& RESEARCH ESSAY PER FACULTY

\begin{tabular}{ccc}
\hline \hline FCA (173) & $136-79 \%$ & $109-63 \%$ \\
\hline FCC (101) & $87-86 \%$ & $81-81 \%$ \\
\hline FCE (155) & $108-70 \%$ & $81-52 \%$ \\
\hline FCG (174) & $143-82 \%$ & $109-63 \%$ \\
\hline FCN (77) & $55-71 \%$ & $38-49 \%$ \\
\hline FCS (160) & $149-93 \%$ & $118-79 \%$ \\
\hline \hline
\end{tabular}

\section{LITERARY DEVELOPMENTS}

In its mission to deliver relevant academic courses in Literature at the Foundation Certificate, Diploma, Degree and post-graduate level, the EFL Department has made a conscious effort to promote the study of Pacific literatures and literary texts of relevance to post-colonial communities with indigenous populations such as is found in Samoa. The old traditional canon of English literature in the $19^{\text {th }}$ and $20^{\text {th }}$ Centuries along with Shakespeare along with a 200 level Survey course which gives a wide sweep from Chaucer to the Romantics is also offered to give students majoring in English Literature the broadest possible base on which to deepen their appreciation of Literary studies.

Thus, with the Foundation Literature Course, HEN005, First Year Degree Course HEN 101, Introduction to Literary Studies and the three courses streamed as post - colonial, World Literatures in English HEN103, HEN201 AND HEN303, it has been the practice to include as many Pacific writers as possible, not only the major ones like Albert Wendt, Konai Helu Thaman and Ruperake Petaia but newer writers such as Figiel, Mila, Avia, Tusitala Marsh, Kamali and Westerlund. Such poetic compositions and collections from the Pacific Islander (PI) diaspora are important examples of post-colonial creative writing, where labels, names and stereotypes are connected to and woven into the vexed issue of cultural identities, (pp. 22-23) [14].

Lecturers from the Samoan Language and Culture Department of NUS who are experts at traditional storytelling as well as the performing arts of dance, song and comedy, are usually invited to deliver lectures on the Oral Literatures of Samoa and especially recite the many and differing versions of fagogo for students in HEN005 and HEN103. Such performances raise the interest of the learners in their own village folklore and tales which they then can research and perform for internal assessment in tutorials, (pp. 22-23) [14]. Indigenous concepts such as the $v a$, defined by Lilomaiava-Doktor (2009) as "social space" (p. 1) [15] or "place, distance and connectedness" (p. 1) [15] are also woven into analysis and discussions around the fiction of Albert Wendt and Sano Malifa in the post-colonial degree courses which enables Samoan learners to understand and critically appreciate the cultural contextualization of such literary productions. Hau'ofa's satirical stories and novels are enjoyed by students for their Pacific humour and serious applications to everyday life and fa'alavelave (cultural obligations). Oilei, one of the major characters of Hau'ofa's fiction is also symptomatic of the post-colonial condition of dependency, signalled by the use of the word Oilei which is "a Fijian word used to express pain, surprise, shock or resignation in tragic or comic situations," (p.198) [16]. In Hau'ofa's fiction, the sound of this oilei "is an anguished yell which incorporates all the agony of the colonized of the world, all the 'wretched of the earth' as well as the narrative stance of defiant laughter which mocks and taunts absurdity," (p.198) [16]. Invariably, laughter in the classroom turns to serious consideration of the many socio-economic problems Hau'ofa exposes in his narratives about our contemporary Pacific communities and their respective diasporas. The problems of access and cost of texts, both for the lecturers and students are often solved by the practice of providing photocopies which is now under scrutiny because of recent copyright and intellectual property laws passed by the Samoan Parliament.

Other important developments include the fact that the Department has convened Literary Conferences and Festivals, two in 2004 and 2007 ( $9^{\text {th }}$ and 10TH SPACLALS Triennial Conferences) and the others in 2012 and 2015 (SPACLALS NUS Branch Literary Festivals) focussing on the Languages and Literatures of the South Pacific as well as fostering creative writing and performance arts in the schools, in the University and within the wider local, regional and international Commonwealth community. In keeping with the vision of NUS as a 'vibrant and innovative centre of excellence in research, Samoan studies and quality learning, teaching and training across all disciplines" (p. 4) [7], the EFL Department has convened and hosted four international events.

The initial conference hosted by the Department, the 9th Triennial Conference of the South Pacific Association for Commonwealth Literature and Language Studies (SPACLALS) with the theme of "Culture, Crisis and Change in Oceania" occurred on the 24-26 November. The 27 speakers represented an international array of academics and other individuals in the field who were interested in the theme and topics presented. They came from Japan, United Kingdom, New Zealand, Australia, Fiji, the USA including Hawaii, Tahiti, American Samoa and other local Samoan academics, writers and participants. "The range of papers presented examined literary and cinematic representations of the Pacific and Australasia, the position of children in Samoa, globalization and gender stereotypes, literacy and writing in the vernacular, foreign language teaching and teaching methods in Samoa, liminal forms of cultural productions such as hip-hop and children's books, cultural practices in Western Polynesia, the politics of intercultural theatre, American Samoa literature and other comparative literatures and postcolonial identity issues in the South 
Pacific", (p.1) [17].

Since this was the first SPACLALS Conference hosted by the convenors at NUS, it provided excellent opportunities for academics in the Committee to expand their experience in managing an event such as this as well as achieving our Conference objectives of "facilitating open communication, cross-cultural understanding, academic exchanges and development along with promoting the culture of peace through language and literature", (p. 2) [17]. The 10th Triennial Conference in November 2007 followed with the theme of "Images, Ideologies and Realities in Oceania". The 25 speakers who presented papers came from New Zealand, Australia, India, Hawaii, Fiji and Samoa and quite a few of the papers focused on the problems of literacy throughout Oceania with multi-layered and complex multiple courses involved including those factors relating to culture. Other topics were visited including "tourism, the changing faces and cultures of Pasifika peoples as globalization hits close to home, the images and realities of Island versus American identity, methods of teaching, a moving paper on the unrecognized Pacific Island men who are members of the 28th Maori Battalion and a controversial paper on the changing face of the Church, in particular the practice of giving", (p.12) [18]. The Conference was successful in that it offered opportunities for local academics to present and expand their intellectual experiences as well as providing "a forum for cross cultural understanding, academic exchanges and development through language and literature", (p.12) [18].

In November 2012, the Department launched a Literary Festival under the umbrella of SPACLALS whose Executive had moved to the University of Auckland, to coincide with the celebration of the 50th Anniversary of Samoa's regaining of political independence. The theme of the Literary Festival was "Pacific Literatures and the Blue Continent: Dreams and Realities". The 24 speakers who presented papers and performances came from New Zealand, Tonga, Fiji, India and Samoa and the variety of topics covered story-telling and e-publishing, reviews of recent Samoan films such as 'The Tulafale', diasporic identities and afakasi realities along with women's issues such as the representation of violence in fiction, the impact of text messaging on the English language learning and writing, critical thinking skills, culturally responsive teaching and learning practices, the realities of reading competencies and difficulties, human rights education in media and journalism, gender issues in the English Department and personal journeys and profiles. The $2^{\text {nd }}$ Literary Festival in December, 2015 focussed on 'Stories of the Pacific: Mixing the Creative and Critical in Representations of the' Believable Worlds' of Oceania." There were 28 presentations, two of which were dramatic performances with 9 international speakers coming from Aotearoa New Zealand, Fiji and Australia. Presentations addressed the analysis of mixing law, humanities, social sciences and Pacific studies in critiques of Pacific-ness, gender and dramatic representations, gender- based violence and youth matters, wayfinding as close reading, contemporary perspectives on Pacific writers, invoking land, culture, language and commerce in the mix of the creative and the critical and literacy and globalisation especially with regards to the acquisition of competencies in both English and Samoan. A highlight of the 2015 Festival was a Festival Fiafia held at the Robert Louis Stevenson Museum providing a twilight tour of the Residence of the Scottish writer known as Tusitala, 'Teller or Writer of Tales' who lived his last six years in Samoa at Vailima till his death in early December, 1894 and whose body is buried on top of Mount Vaea overlooking the Museum. The venue was provided gratis as part of the Board of Trustees Sponsorship for the Festival to promote literacy and literary studies.

All four literary events in 2004, 2007, 2012 and 2015 had a focus on writers with Writers' and Readers' Forums or Talanoa Sessions where established and newly published writers could be showcased along with a Young Writers' Forum introduced in the latter events to allow the prize winners from the Annual Short Story Competition, organized by Bluesky Samoa, Samoa Stationery and Books (SSAB) and the Newspapers In Education (NIE) section of the Samoa Observer, to participation in the Literary Festival as the new and up and coming generation of creative writers. These young writers ranged in age from 8 to 18 years of age. The usual book launches and art exhibitions by local artists as well as poetry readings were also included in all four event programmes.

In the 2012 Festival, a Wearable Art Fashion Show by NUS students as well as spoken word performances, monologues and other productions by lecturers such as Fiona Collins in the Performing Arts section of the Expressive Arts Department of the Faculty of Education and more recently, a part time Lecturer for the EFL Department were offered as part of the mixed platter of Festival events. A unique addition to the 2012 Festival was the inclusion of the prize winners from the Samoa 50th Independence Secondary Schools Drama Competition organized by the Rotaract Club of Apia. Students from St Mary's College and Faatuatua Christian College dramatized 'Sina and the Eel' and 'The Arrival of Christianity in Samoa' respectively to a very appreciative audience. This community outreach and an attempt to link 'town and gown' as well as to construct a literary bridge between the generations is an on-going effort by the Department to make language and literary studies authentic and relevant.

\section{CONCLUSION}

Global conditions are vexed by many dilemmas involving social unrest, unemployment, migration and inequality which becomes more apparent every day. Samoa is a member of the SIDS group of the U.N family of nations. Sustainable development is strategic and all important in these post-colonial times. Many of the important challenges regarding literacy at NUS demand real responses by an increase in budget and resources support. In trying to "grow our own" graduates and upgrade or up-skill lecturers for a sustainable Samoa in the new millennium, we continue to face many challenges but our hopes and aspirations remain positive and strategic, using the few resources and limited budget we have, to hopefully make a real difference in our contemporary world. Generally the EFL Department takes change in its stride and attempts to cope with the pressures of growing expectations from our major community 
stakeholders. The lecturers continue to support a broad strategic Faculty plan and vision towards tertiary education that is inclusive of local and global initiatives for development in the Sector, whilst keeping in mind our fundamental Samoan traditions and cultural values from which we draw our strength for personal, collective and institutional growth.

\section{REFERENCES}

[1] UNDP, "United Nations System in Samoa," UNDP Office, Apia, 2015.

[2] A. So'o, "History of the University," in National University of Samoa Calendar, NUS, Apia, pp. 45-46, 2016.

[3] F. Asi, NUS Budget 2016/2017, National University of Samoa, Apia.

[4] United Nations Department of Economic and Social Affairs: Samoa Population. (2017). [Online]. Available: http://countrymeters.info./en/Samoa

[5] EQAP, Pacific Benchmarking for Education Results (PaBER) Samoa Report, Educational Quality Assessment Programme (EQAP), Suva, Fiji, 2016.

[6] P. Kral, "The Status of English in Samoa," US Embassy Office, Apia, 2010.

[7] National University of Samoa, NUS Corporate Plan 2012-2014, National University of Samoa, Apia, 2012.

[8] V. Heem and S. Vaai, "Report for EFL department courses," EFL Department, National University of Samoa, Apia, 2005.

[9] Faculty of Arts, FOA Strategic Plan, 2012-2014, National University of Samoa, Apia, 2012.

[10] S. Vaai and V. Heem, "Focus on Reading: Initiatives with PELT and SRA Laboratories in the EFL Department at NUS," in SPAN 67, S Vaai, Ed. University of Auckland, New Zealand, pp. 23-44, 2014.
[11] S. Vaai, T. V. Heem, K. Arp, and E. Koria, "Reading: A matter of minds and means: Focus on reading for foundation and first year students at the national university of Samoa," The Journal of Samoan Studies, vol. 3, pp. 21-35, 2010.

[12] D. Parker, Teacher's Handbook SRA Reading Laboratory 3b, SRA McGraw-Hill, Ohio, USA, 2006.

[13] S. Vaai and V. Heem, "The challenges to proficiency in English; innovations and strategies for foundation students at NUS," presented at PIURN Conference, National University of Samoa, Apia, September 2016

[14] S. Vaai, The Challenges of Teaching Pacific Literatures, in S. Marsh, Ed. SPAN 63, University of Auckland, New Zealand, pp. 10-27, 2010.

[15] S. Lilomaiava-Doktor, "Beyond "Migration": Samoan population movement (Malaga) and the geography of social space (Va)," The Contemporary Pacific, vol. 21, no. 1, pp. 1-32, University of Hawaii Press, Hawaii, 2009.

[16] S. Vaai, Literary Representations in Western Polynesia: Colonialism and Indigeneity, Apia, National University of Samoa, 1999.

[17] S. Vaai and V. Heem, "Report on SPACLALS 9th Triennial Conference," in S. Va'ai, Ed. SPAN 54/55, pp. 1-2, Faculty of Arts, National University of Samoa, Apia, 2005.

[18] V. Heem and S. Vaai, "Report on the English and foreign language (EFL) department," Faculty of Arts, National University of Samoa, Apia, 2014.

Sina Va'ai is currently the Professor of English in the Faculty of Arts at the National University of Samoa. She completed her PhD thesis at the University of Canberra in 1995 which was published in 1999 on the topic of Literary Representations in Western Polynesia. Her research interests are in post-colonial literary representations in Pacific literatures, literacy, reading and creative writing. She is a published poet and a member of the Samoa Arts Council. 